Article

\title{
Changes in Intestinal Gene Expression of Zebrafish (Danio rerio) Related to Sterol Uptake and Excretion upon $\beta$-Sitosterol Administration
}

\author{
Mai Takase and Hideki Ushio * \\ Graduate School of Agricultural and Life Sciences, The University of Tokyo, 1-1-1 Yayoi, Tokyo 113-8657, Japan; \\ danzhime.anden.see@gmail.com \\ * Correspondence: aushio@mail.ecc.u-tokyo.ac.jp; Tel.: +81-3-5841-5300
}

Received: 21 November 2017; Accepted: 27 December 2017; Published: 4 January 2018

\begin{abstract}
Replacement of fishmeal with plant ingredients will introduce not only plant oil and protein but also phytosterol to the fish diet. Mammals strictly restrict the uptake of phytosterol at intestinal epithelial cells by regulating the gene expressions of sterol uptake and excretion proteins; however, phytosterol is found in the fish muscle and other organs. In order to assess the ability of phytosterol uptake by the intestinal epithelial cells of fish, no-sterol diet, cholesterol-, and $\beta$-sitosterol-containing diet was separately administered to zebrafish, and the relative mRNA expressions related to sterol uptake and excretion were evaluated. Gene expression of Niemann-Pick C1-like protein 1 in the sitosterol-fed group was significantly higher than that of the cholesterol-fed group $(p<0.05)$. The expression of apolipoprotein A-I gene was also higher in the sitosterol-fed group than that in the no-sterol and cholesterol-fed groups. The expressions of ATP-binding cassette, sub-family G, member 5 and 8, were significantly higher in the sitosterol-fed group, compared to the no-sterol group. Regarding the gene expression of ATP-binding cassette sub-family A, member 1 , the sitosterol-fed group showed higher expression level compared to the other groups $(p<0.01)$. These results suggest that fish should be tolerant to phytosterols in contrast to mammals.
\end{abstract}

Keywords: cholesterol; phytosterol; intestinal epithelial cell; gene expression; zebrafish

\section{Introduction}

Fishmeal is an important component of fish diet used in aquaculture [1]. The recent trend in the rise of fishmeal price has led to several studies exploring alternative feed resources for productive aquaculture. The popular substitute for fishmeal is plant ingredient owing to their high amino acid content. Many of the past studies that focused on plant substitutes targeted the effect of oil and protein replacement on fish metabolism [2-4]. It is important to recognize that the substitution of fishmeal with plant ingredients introduces another notable substance, the phytosterol. Several types of phytosterols are found in nature and one of the most common phytosterol is $\beta$-sitosterol.

Uptake of sterols other than cholesterol is strictly controlled in mammals. For example, humans retain approximately 40 to $50 \%$ of dietary cholesterol but less than $5 \%$ of dietary phytosterol $[5,6]$, whereas several fish species accumulate phytosterol in their muscles and other organs [7-10]. Plant-based ingredients are the major sources of phytosterol; however, previous studies have not focused on phytosterol metabolism in fish intestines. Several studies report the transcriptomic changes in gene expression of fish fed plant-based ingredients but those studies are not dedicated to studies of phytosterol and sterol uptake or excretion; related genes remain unstudied [11,12]. Hence, research on the gene expression profile associated with intestinal phytosterol absorption and excretion is required as an important milestone to understand the whole process. 
Dietary sterols are absorbed in the intestine and transported to the liver for further metabolisms. Mammals and zebrafish share similar sterol uptake and excretion molecules in the intestinal epithelial cells. Uptake and excretion processes of dietary sterols are as follows. Dietary sterols enter the small intestinal epithelial cells through Niemann-Pick C1-like protein 1, (NPC1L1) [13], and scavenger receptor class B, member 1 (SR-B1) [14]. SR-B1 was initially recognized as sterol transporting protein but recent studies elucidated that NPC1L1 is specific to sterol uptake, while SR-B1 is not only responsible for the uptake of cholesterol but also other lipids [15,16]. Free sterols are then subjected to esterification by sterol O-acyltransferase 2 (SOAT2) [17]. Esterified sterols are then encapsulated into lipoprotein particles and transported out of the epithelial cells. Apolipoprotein A-I (ApoA-I) is responsible for the formation of pre-high density lipoprotein (HDL) particles in human, which then is associated with sterol transportation from the small intestine to the liver. In zebrafish, ApoA-I also contributes to sterol transporting system [18]. Excessive sterols are excreted out of the cells through the ATP-binding cassette sub-family G, member 5 and 8 (ABCG5 and ABCG8), back into the lumen in mammals [19]. Another ATP-binding cassette, sub-family A, member 1 (ABCA1), also exports sterols from the small intestinal epithelial cells into the circulation to contribute to the formation of HDL particles (Figure 1).

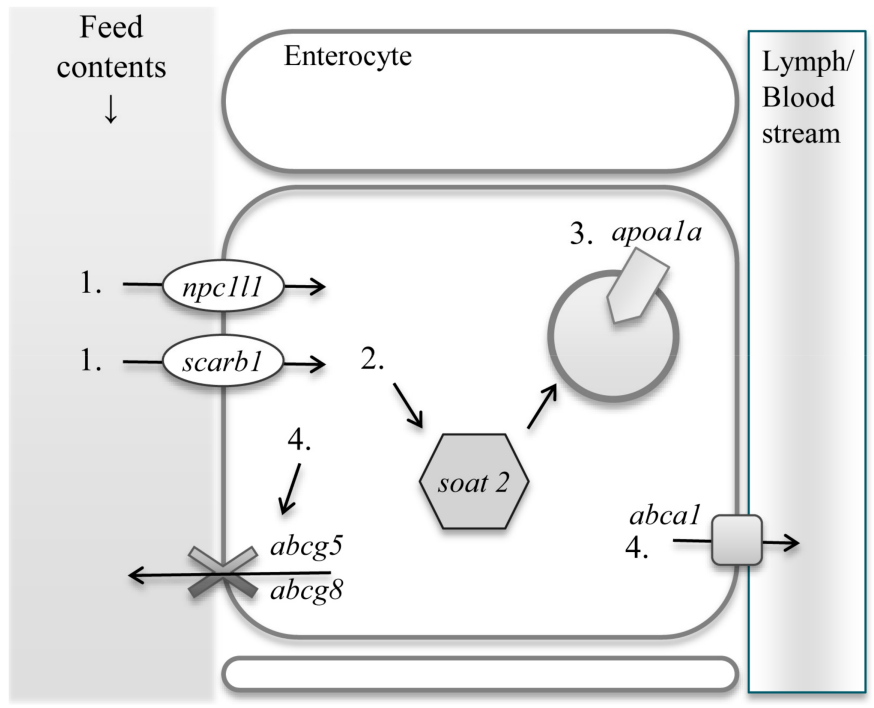

Figure 1. Diagram of sterol uptake and excretion genes. Sterols enter the small intestinal epithelial cells via Niemann-Pick C1-like protein 1 (1. npc1l1) and scavenger receptor class B, member 1 (1. scarb1) and esterified with fatty acid by O-acyltransferase 2 (2. soat2). Esterified sterols are encapsulated with Apolipoprotein A-I (3. apoa1a). Excessive sterols are excreted via ATP-binding cassette sub-family G, member 5 and 8 (4. abcg5/abcg8) and ATP-binding cassette, sub-family A, member 1 (4. abca1). Nomenclature in the parentheses represent gene name. Lipoprotein particles are excreted from intestinal epithelial cells to lymph in mammals, whereas to portal vein in fish.

Changes in gene expressions related to sterol uptake and excretion have been studied in mammalian models. NPC1L1 is responsible for transporting sterols into the small intestinal epithelial cells by targeting sterols. In a previous study, phytosterol was administered to FHs 74 Int cells, small intestine epithelial cell line of human. The administration of phytosterol reduced the expression of npc1l1 [20]. Another gene related to sterol uptake, scavenger receptor class B, member 1 (scarb1), was also followed in the same study but no significant change was observed. The changes in gene expression profiles are imperative to understand the phytosterol metabolisms in fish. The study of fish diet is generally long-term [2-4] but study on the acute or short-term effect is required as one of the important pieces of knowledge to explain the metabolic system as a whole. The aim of this study was to investigate such gene expressions in order to elucidate the effects of phytosterol on fish metabolism, and eventually to enlighten the conception of phytosterol accumulation in fish. 


\section{Results}

\subsection{Relative mRNA Expression Levels of Sterol Uptake Related Genes}

The relative mRNA expression levels of npc1l1 were significantly higher in the sitosterol-fed group than that in the cholesterol-fed group (Steel-Dwass test, $p<0.05$ ). The differences were insignificant between the mRNA expressions of the no-sterol versus the cholesterol-fed groups, and the no-sterol versus the sitosterol-fed groups. The mRNA expression levels were not significantly different among the three groups for scarb1 (Figure 2b).
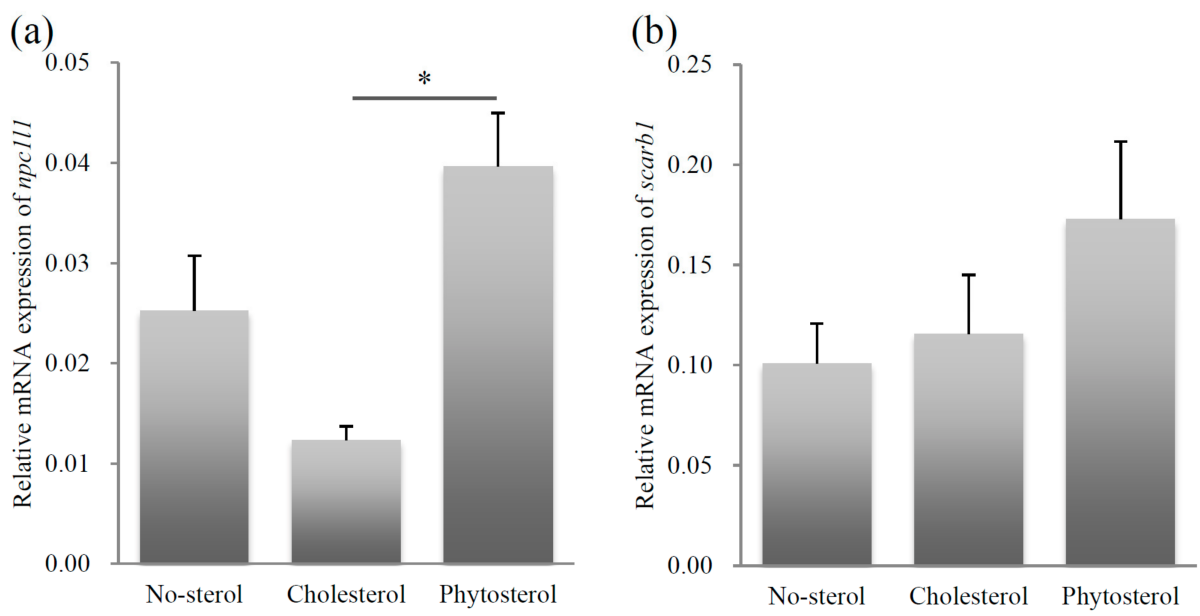

Figure 2. Relative mRNA expression levels of sterol uptake related genes, npc1l1 (a) and scarb1 (b). Left column: no-sterol group, Middle column: cholesterol-fed group, Right column: sitosterol-fed group. Data were expressed as mean \pm standard error (SE) ( $n=10$, per group). Statistically significant difference is shown as $*<0.05$.

\subsection{Relative mRNA Expression of Sterol Modification and Transportation Related Genes}

There was no significant difference of soat 2 mRNA expression level among the three groups (Figure 3a). The Apolipoprotein A-I (apoa1a) expression level in the sitosterol-fed group was significantly higher than that of the no-sterol and the cholesterol-fed groups $(p<0.05)$ (Figure $3 b)$.

(a)

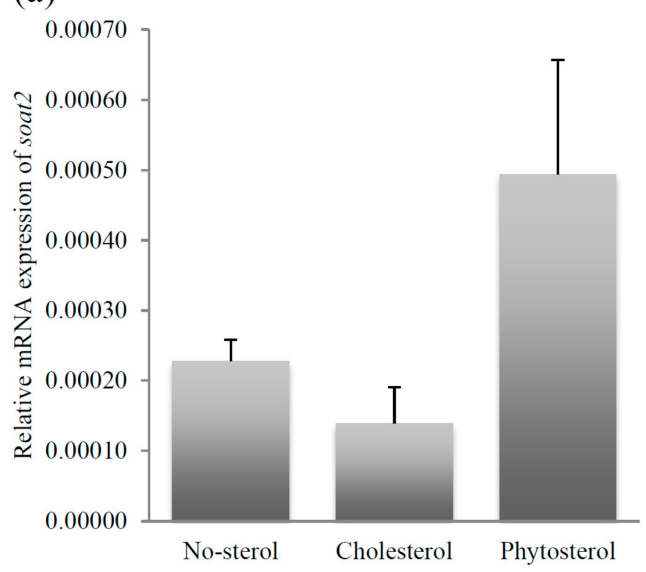

(b)

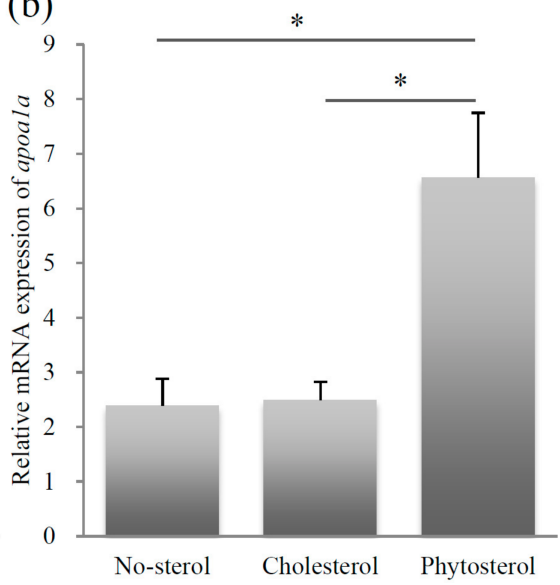

Figure 3. Relative mRNA expression levels of soat2 (a) and apoa1a (b). Left column: no-sterol group, Middle column: cholesterol-fed group, Right column: sitosterol-fed group. Data were expressed as mean $\pm \mathrm{SE}$ ( $n=10$, per group). Statistically significant difference is shown as ${ }^{*} p<0.05$. 


\subsection{Relative mRNA Expression Level of Sterol Excretion Genes}

The relative mRNA expression levels of $a b c g 5$ are shown in Figure 4a. The $a b c g 5$ expression level of the sitosterol-fed group was significantly higher than that of the no-sterol group $(p<0.05)$. Significant differences were also observed between the expression levels of the no-sterol and cholesterol-fed groups $(p<0.05)$. The expression levels of the no-sterol and sitosterol-fed groups were significantly different $(p<0.05)$ for $a b c g 8$ (Figure 4 b). The abcg8 expression levels of the cholesterol-fed group were close to that of the sitosterol-fed group.
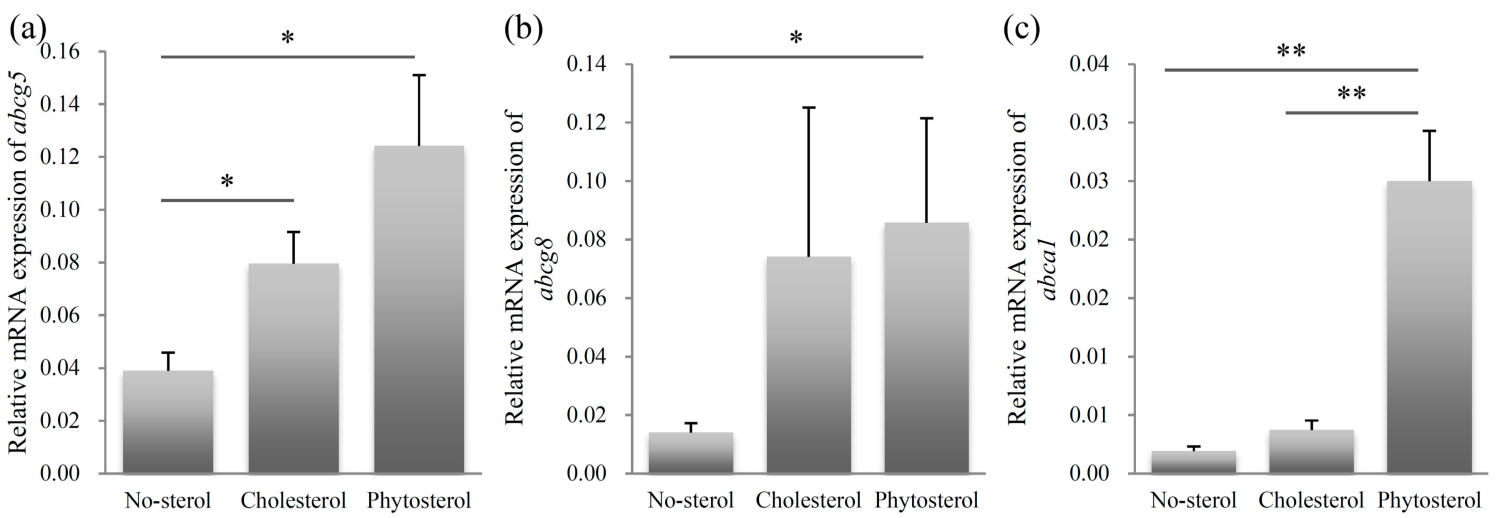

Figure 4. Relative mRNA expression of sterol excretion related genes abcg5 (a), abcg8 (b), and abca1 (c). Left column: no-sterol group, Middle column: cholesterol-fed group, Right column: sitosterol-fed group. Data were expressed as mean $\pm \mathrm{SE}(n=10$, per group). Statistically significant difference is shown as ${ }^{*} p<0.05,{ }^{* *} p<0.01$.

The expression level of $a b c a 1$ in the sitosterol-fed group was significantly higher than that of the no-sterol and cholesterol-fed groups $(p<0.01)$. The difference was not significant between the no-sterol and cholesterol-fed groups.

\section{Discussion}

Study of phytosterol metabolism in fish is reported but perception of sterol uptake and excretion mechanism in intestinal epithelial cells is veiled. Many layer of studies, i.e., studies related to gene and protein expressions, are essential to decipher the whole picture. The aim of this study was to firstly elucidate the sterol uptake and excretion gene expression profile in zebrafish small intestinal epithelial cells by comparing the expression pattern responding to two types of sterols; cholesterol, and $\beta$-sitosterol. The present study proposes that the gene expressions related to sterol uptake and transportation are regulated by the ingested phytosterol in the short term.

NPC1L1 is located at the brush border membrane of enterocytes in mammals [13]. A study using a human FHs 74 Int cell line reported that the mRNA expression level of npc1l1 was the highest in the cholesterol-deprived cells and the expression level decreased with cholesterol or sitosterol administration [20]. The difference between no-sterol group and cholesterol-fed group was not significant. Cholesterol may not suppress the expression of npc1l1 in fish as strong as it did in the mammalian model. The result of npc1l1 expression level in sitosterol administered FHs Int cell was the opposite from the gene expression of sitosterol-fed group in this study. The ability of NPC1L1 to uptake cholesterol may have led to increase in npc1l1 expression to substitute the lack of dietary cholesterol in the no-sterol and sitosterol-fed groups. The enhance of npc1l1 expression in the sitosterol-fed group suggests that sitosterol could directly or indirectly affect the concerned gene expressions. The increase in $n p c 111$ gene expression would lead to additional phytosterol uptake into the small intestinal epithelial cells. If fish require phytosterol, it can be assumed that phytosterol is intentionally absorbed to be utilized in the further metabolism. 
The case of SR-B1 was different from that of NPC1L1. A previous study reported that SR-B1 deficient mice showed no change in the intestinal cholesterol absorption compared to the wild-type mice [14]. These findings review that SR-B1 is not heavily responsible for sterol uptake and scarb1 expression might not be modulated by dietary sterols. SR-B1 was recognized as an important sterol transporter but deficiency of SR-B1 did not alter the cholesterol concentration in mammals [13,21]. These findings show that amount of imported cholesterol via SR-B1 is less compared to NPC1L1 and lipid source is required for absorption via SR-B1. In the present study, all of the individuals were administered the same amount of oil and with the same fatty acid contents, which might be the reason for similar scarb1 expression levels in all groups. SR-B1 also interacts with bile micelles and down regulation of SR-B1 was observed in rodents with bile delivery deficiency [22]. Ingested cholesterol will eventually reach hepatocyte and be converted to bile acid. There is a possibility of phytosterol affecting bile acid metabolism. Interference of bile acid production by $\beta$-sitosterol to may eventually lead to down regulation of SR-B1. Administration of phytosterol might change the scarb1 expression in the long run.

After entering the intestinal epithelial cells by function of NPC1L1 or SR-B1, sterols are subjected to further modification by SOAT2 into ester forms. The relative mRNA expression of soat 2 was very low in all the groups and was not affected by the administration of different sterols, implying that zebrafish SOAT2 mRNA expression would not be regulated by dietary sterols. A conventional study in mammalian models demonstrated that SOAT2 distinguished cholesterol from various types of sterols [17]. Zebrafish SOAT2 function should be investigated regarding sterol esterification.

Zebrafish is used as one of the model organisms to study the apolipoprotein trafficking mechanism in humans [18]. ApoA-I is an important component of high-density lipoprotein in mammals and a similar protein is also reported in the zebrafish. The expression of apoa1a was high in the sitosterol-fed group compared to the cholesterol-fed group. The mRNA expression level of apoa1a in the cholesterol-fed group was similar to that of the level in the no-sterol group. This result suggests that dietary administration of $\beta$-sitosterol would enhance the ApoA-I protein expression in zebrafish. The change in the expression of apoa1a could be attributed to the similar expression profile observed in npc1l1 expression level of fish group fed with sitosterol. Npc1l1 expression was enhanced by $\beta$-sitosterol administration in zebrafish, possibly leading to increased dietary $\beta$-sitosterol uptake and to enhance apoa1a expression to export $\beta$-sitosterol out of the intestinal epithelial cell.

Non-esterified sterols are excreted from the cell via ABCG5 and ABCG8 and/or ABCA1 transporters in mammals. Mutation in the expression of abcg5 and abcg 8 genes is known to be the cause for sitosterolemia, a disease that result in high concentration of blood $\beta$-sitosterol in humans. The export of excessive sterols via these proteins is thus crucial to maintain cellular sterol homeostasis [23]. Gene expressions of $a b c g 5$ and $a b c g 8$ were the lowest in the no-sterol group in this study, suggesting that the gene expressions would be enhanced partially by dietary sterols. There was no significant difference in the mRNA expressions between the cholesterol- and the sitosterol-fed groups, which implied that sterol molecular species were not involved in the enhancement of $a b c g 5$ and abcg8 expressions in zebrafish.

For ABCA1, a study using Caco-2 cells reported that application of mixed micelles enriched with sitostanol enhanced ABCA1 expression [24]; ABCA1 expression would be more sensitive to sitosterol in mammals. Expression level of $a b c a 1$ was significantly higher in the sitosterol-fed group, in comparison to the no-sterol and the cholesterol-fed groups in this study. The expression of zebrafish abca1 might be modulated by dietary $\beta$-sitosterol, similar to the mammalian models. This research showed upregulated expression of npc1l1 and apoa1a in the sitosterol-fed group. This notable expression in the sitosterol-fed group may lead to $\beta$-sitosterol transportation to circulatory system.

The overall trend between the cholesterol- and sitosterol-fed groups showed that the administration of phytosterol would upregulate the gene expression responsible for sterol uptake to intestinal epithelial cells and further transportation to hepatocyte, suggesting the possibility of high 
sitosterol uptake in fish, which is different from those of mammalian model. Fish might actively uptake $\beta$-sitosterol for utilization.

Further studies about the use of phytosterols are necessary for the deeper understanding of fish strategies against phytosterols.

\section{Materials and Methods}

\subsection{Fish}

Mature wild-type zebrafish (Danio rerio) with size of approximately $3 \mathrm{~cm}$ were purchased from Masuko Co., Ltd. (Kuki, Japan). Zebrafish were kept in a 35-L water tank under 12L/12D (08:00-20:00 light) cycle at a constant temperature of $25^{\circ} \mathrm{C}$. All animal care and use guidelines were followed according to the institutional protocol and approved by the University of Tokyo (P17-093, \#AIMCB-404).

\subsection{Feed Production}

Diet composition is shown in Table 1. Cholesterol was purchased from Sigma-Aldrich (Tokyo, Japan) and $\beta$-sitosterol was purchased from Tama Biochemical Co., Ltd. (Tokyo, Japan), both with purity of $>99 \%$. Casein, cornstarch, vitamin mix and mineral mix were purchased from Oriental Yeast Co., Ltd. (Tokyo, Japan). Arginine and taurine were purchased from Wako Pure Chemical Industries, Ltd. (Osaka, Japan). Cysteine and corn oil were purchased from Sigma-Aldrich. Sterols in corn oil were removed by column chromatography.

Table 1. Composition of three types of diet in percentage.

\begin{tabular}{cccc}
\hline Contents & No-Sterol & Cholesterol & Sitosterol \\
\hline Casein & 69.9 & 67.9 & 67.9 \\
Arginine & 0.4 & 0.4 & 0.4 \\
Cysteine & 0.9 & 0.9 & 0.9 \\
Taurine & 4.4 & 4.3 & 4.3 \\
Oil $^{1}$ & 9.6 & 9.3 & 9.3 \\
Cornstarch & 10.1 & 9.8 & 9.8 \\
Vitamin mix & 1.0 & 1.0 & 1.0 \\
Mineral mix & 3.5 & 3.4 & 3.4 \\
Choline Cl & 0.2 & 0.2 & 0.2 \\
Sterol & 0 & 3.0 & 3.0 \\
\hline Total & 100 & 100 & 100 \\
\hline \multicolumn{1}{c}{ 1 Corn oil with out sterol contents was used. }
\end{tabular}

${ }^{1}$ Corn oil with out sterol contents was used.

The feed dough was passed through the sieve of with mesh diameter of $850 \mu \mathrm{m}$ to obtain uniformity in size. Then, it was subjected to freeze-thaw drying over night.

\subsection{Sampling}

The zebrafish were fed with a commercial fish diet for acclimation to the experimental conditions; and were fasted for two days prior to feeding experiment to avoid the effects of commercial diet. Fish searched for food near the surface of the water when fasted. Fish were fed ad libitum enough to start swimming at the middle layer of water tank. This behavior was used as indicator of saturated feeding. The remaining diets were removed by using fish net.

Our preliminary trials revealed that the diet reached the end of the zebrafish small intestine of zebrafish in approximately $6 \mathrm{~h}$ (data not shown). Hence, the sampling time was set at $6 \mathrm{~h}$ post feeding. Fish were fed at 10:00 am, $2 \mathrm{~h}$ after the onset of light, and sampled $6 \mathrm{~h}$ after feeding. Fish were randomly sampled with no preference of sex. Ten individuals were collected for each diet group and 
immediately transferred to ice water for euthanasia. Ingested feed and feces were removed from inside of the intestine. The intestine was excised, cleaned carefully, immersed in $300 \mu \mathrm{L}$ RNAlater (Thermo Fisher Scientific Japan K.K., Yokohama, Japan), and stored at $-30{ }^{\circ} \mathrm{C}$ until use.

\subsection{Real Time PCR}

RNeasy Lipid Tissue Mini Kit (QIAGEN, Hilden, Germany) was used for the total RNA extraction according to the manufacturer's instructions. The resulting samples were subjected to the following reverse transcription reaction using Takara Prime Script RT Reagent Kit with a $g$ DNA Eraser (Takara Bio Inc., Kusatsu, Japan) in a GeneAmp PCR System 9700 (Thermo Fisher Scientific Japan K.K., Yokohama, Japan) using the temperature and time protocol at $37^{\circ} \mathrm{C}$ for $15 \mathrm{~min}, 85^{\circ} \mathrm{C}$ for $5 \mathrm{~s}$, and finally stored at $4{ }^{\circ} \mathrm{C}$ until use.

Primers for the real-time PCR were designed using the National Center for Biotechnology Information database. Primers were designed either by using Primer-BLAST and Primer 3 Plus [25] and checked for amplification efficiency. Primers with efficiency close to reference gene were selected. Primer sequences are listed in Table 2.

Table 2. Gene name and primer sequence for real-time PCR.

\begin{tabular}{cccc}
\hline Gene & Forward Primer $\mathbf{( 5}^{\prime} \mathbf{- 3}^{\prime} \mathbf{)}$ & Reverse Primer $\mathbf{( 5}^{\prime} \mathbf{- 3}^{\prime} \mathbf{)}$ & Accession \\
\hline npc1l1 & GGACTGGCGGGATCAT & GCCGAGAGCTGTGATG & XM_009304174.2 \\
scarb1 & TTCCACATCGTCAATC & CCACAGACATGCTCTC & NM_198921.2 \\
soat2 & TGGAACTCCACTTCGT & GTCAAACACTCACCCA & XM_017356504.1 \\
apoa1a & GGACGGAACCGACTAT & GGAGGTGGTCTGGGCA & NM_131128.1 \\
abcg5 & CTGGCAGAGCTGGCTA & AAACACCAGCTCCCT & NM_001128690.1 \\
abcg8 & CATGGCACTGTTTGTG & AAACCAAGACGCCACC & XM_005156538.3 \\
abca1a & CAGTATGGCATCCCTC & TCCATCCGCATTTCTC & NM_001309465.1 \\
$r p l 8$ & AATCCACACCGGCCAG & GCCAACGGGAAGCACA & NM_200713.1 \\
\hline
\end{tabular}

SYBR 96-well plate was used for the real-time PCR. Premix Ex Taq II (Tli RNaseH Plus) was used for the real-time PCR. $10 \mu \mathrm{L}$ of SYBR Premix Ex Taq II (Tli RNaseH Plus) $(2 \times)(10 \mu \mathrm{L}), 0.8 \mu \mathrm{L}$ of PCR forward primer $(10 \mu \mathrm{M}), 0.8 \mu \mathrm{L}$ of PCR reverse primer $(10 \mu \mathrm{M}), 0.4 \mu \mathrm{L}$ of ROX Reference Dye $(50 \times)$, and $6 \mu \mathrm{L}$ of distilled water was mixed with $2 \mu \mathrm{L}$ of template in each well. A Fast Real-Time PCR System 7300 (Thermo Fisher Scientific Japan K.K., Yokohama, Japan) was used for the detection. Real-time PCR was performed according to the manufacturer's instruction. Preliminary trials revealed that $r p l 8$ was the most suitable reference gene compared to other genes such as actin, gapdh, 16s, and rpl6. The melting curve was checked for uniformity with in each gene.

\subsection{Statistical Analysis}

The average of the data obtained was calculated using the values from ten individuals. Out-of-range values were discarded using the Smirnov-Grubbs test. Error bars represent standard errors. Statistical comparison was performed using the Steel-Dwass test.

Acknowledgments: This study was supported in part by a grant from the Japanese Ministry of Education, Culture, Sports, Science and Technology.

Author Contributions: M.T. and H.U. conceived and designed the experiments; M.T. performed the experiments; M.T. analyzed the data; H.U. contributed to reagents/materials/analysis tools; M.T. and H.U. wrote the paper.

Conflicts of Interest: The authors declare no conflict of interest. 


\section{References}

1. Olsen, R.L.; Hasan, M.R. A limited supply of fishmeal: Impact on future increases in global aquaculture production. Trends Food Sci. Technol. 2012, 27, 120-128. [CrossRef]

2. Burel, C.; Boujard, T.; Escaffre, A.M.; Kaushik, S.J.; Boeuf, G.; Mol, K.A.; Van der Geyten, S.; Kühn, E.R. Dietary low-glucosinolate rapeseed meal affects thyroid status and nutrient utilization in rainbow trout (Oncorhynchus mykiss). Br. J. Nutr. 2000, 83, 653-664. [CrossRef] [PubMed]

3. Morais, S.; Pratoomyot, J.; Taggart, J.B.; Bron, J.E.; Guy, D.R.; Bell, J.G.; Tocher, D.R. Genotype-specific responses in Atlantic salmon (Salmo salar) subject to dietary fish oil replacement by vegetable oil: A liver transcriptomic analysis. BMC Genom. 2011, 12, 255-272. [CrossRef] [PubMed]

4. Torrecillas, S.; Robaina, L.; Caballero, M.; Montero, D.; Calandra, G.; Mompel, D.; Karalazos, V.; Kaushik, S.; Izuquierdo, M.S. Combined replacement of fishmeal and fish oil in European sea bass (Dicentrarchus labrax): Production performance, tissue composition and liver morphology. Aquaculture 2017, 474, 101-112. [CrossRef]

5. Gould, R.G.; Jones, R.J.; LeRoy, G.V.; Wissler, R.W.; Taylor, C.B. Absorbability of beta-sitosterol in humans. Metabolism 1969, 18, 652-662. [CrossRef]

6. Salen, G.; Ahrens, J.E.; Grundy, S. Metabolism of beta-sitosterol in man. J. Clin. Investig. 1970, 49, $952-967$. [CrossRef] [PubMed]

7. Kritchevsky, D.; Tepper, S.; DiTullo, N.; Holmes, W. The sterols of seafood. J. Food Sci. 1967, 32, 64-66. [CrossRef]

8. Miller, M.R.; Nichols, P.D.; Carter, C.G. The digestibility and accumulation of dietary phytosterols in Atlantic salmon (Salmo salar L.) smolt fed diets with replacement plant oils. Lipids 2008, 43, 549-557. [CrossRef] [PubMed]

9. Morris, R.; Ballantine, J.; Roberts, J.; Lavis, A. The sterols of some marine teleosts. Comp. Biochem. Physiol. Part B Comp. Biochem. 1982, 73, 481-484. [CrossRef]

10. Ozyurt, G.; Kuley, E.; Etyemez, M.; Ozoğul, F. Comparative seasonal sterol profiles in edible parts of Mediterranean fish and shellfish species. Int. J. Food Sci. Nutr. 2013, 64, 476-483. [CrossRef] [PubMed]

11. Krol, E.; Douglas, A.; Tocher, D.R.; Crampton, V.O.; Speakman, J.R.; Secombes, C.J.; Martin, S.A.M. Differential responses of the gut transcriptome to plant protein diets in farmed Atlantic salmon. BMC Genom. 2016, 17, 156. [CrossRef] [PubMed]

12. Tacchi, L.; Secombes, C.J.; Bickerdike, R.; Adler, M.A.; Venegas, C.; Takle, H.; Martin, S.A.M. Transcriptomic and physiological responses to fishmeal substitution with plant proteins in formulated feed in farmed Atlantic salmon (Salmo salar). BMC Genom. 2012, 13, 363. [CrossRef] [PubMed]

13. Altmann, S.W.; Davis, H.R.; Zhu, L.J.; Yao, X.; Hoos, L.M.; Tetzloff, G.; Iyer, S.P.; Maguire, M.; Golovko, A.; Zeng, M.; et al. Niemann-Pick C1 Like 1 protein is critical for intestinal cholesterol absorption. Science 2004, 303, 1201-1204. [CrossRef] [PubMed]

14. Abumrad, N.A.; Davidson, N.O. Role of the gut in lipid homeostasis. Physiol. Rev. 2012, 92, $1061-1085$. [CrossRef] [PubMed]

15. Bietrix, F.; Yan, D.; Nauze, M.; Rolland, C.; Bertrand-Michel, J.; Comera, C.; Schaak, S.; Barbaras, R.; Groen, A.K.; Perret, B.; et al. Accelerated lipid absorption in mice overexpressing intestinal SR-BI. J. Biol. Chem. 2006, 281, 7214-7219. [CrossRef] [PubMed]

16. Hauser, H.; Dyer, J.H.; Nandy, A.; Vega, M.A.; Werder, M.; Bieliauskaite, E.; Weber, F.E.; Compassi, S.; Gemperli, A.; Boffelli, D.; et al. Identification of a receptor mediating absorption of dietary cholesterol in the intestine. Biochemistry 1998, 37, 17843-17850. [CrossRef] [PubMed]

17. Temel, R.E.; Gebre, A.K.; Parks, J.S.; Rudel, L.L. Compared with Acyl-CoA: Cholesterol O-acyltransferase (ACAT) 1 and lecithin: Cholesterol acyltransferase, ACAT2 displays the greatest capacity to differentiate cholesterol from sitosterol. J. Biol. Chem. 2003, 278, 47594-47601. [CrossRef] [PubMed]

18. Otis, J.P.; Zeituni, E.M.; Thierer, J.H.; Anderson, J.L.; Brown, A.C.; Boehm, E.D.; Cerchione, D.M.; Ceasrine, A.M.; Avraham-Davidi, I.; Tempelhof, H.; et al. Zebrafish as a model for apolipoprotein biology: Comprehensive expression analysis and a role for ApoA-IV in regulating food intake. Dis. Model Mech. 2015, 8, 295-309. [CrossRef] [PubMed] 
19. Tsubakio-Yamamoto, K.; Nishida, M.; Nakagawa-Toyama, Y.; Masuda, D.; Ohama, T.; Yamashita, S. Current therapy for patients with sitosterolemia-effect of ezetimibe on plant sterol metabolism. J. Atheroscler. Thromb. 2010, 17, 891-900. [CrossRef] [PubMed]

20. Jesch, E.D.; Seo, J.M.; Carr, T.P.; Lee, J.Y. Sitosterol reduces messenger RNA and protein expression levels of Niemann-Pick C1-like 1 in FHs 74 Int cells. Nutr. Res. 2009, 29, 859-866. [CrossRef] [PubMed]

21. Bura, K.S.; Lord, C.; Marshall, S.; McDaniel, A.; Thomas, G.; Warrier, M.; Zhang, J.; Davis, M.A.; Sawyer, J.K.; Shah, R.; et al. Intestinal SR-BI does not impact cholesterol absorption or transintestinal cholesterol efflux in mice. J. Lipid Res. 2013, 54, 1567-1577. [CrossRef] [PubMed]

22. Voshol, P.J.; Schwarz, M.; Rigotti, A.; Krieger, M.; Groen, A.K.; Kuipers, F. Down-regulation of intestinal scavenger receptor class $\mathrm{B}$, type I (SR-BI) expression in rodents under conditions of deficient bile delivery to the intestine. Biochem. J. 2001, 356, 317-325. [CrossRef] [PubMed]

23. Berge, K.E.; Tian, H.; Graf, G.A.; Yu, L.; Grishin, N.V.; Schultz, J.; Kwiterovich, P.; Shan, B.; Barnes, R.; Hobbs, H.H. Accumulation of dietary cholesterol in sitosterolemia caused by mutations in adjacent ABC transporters. Science 2000, 290, 1771-1775. [CrossRef] [PubMed]

24. Plat, J.; Mensink, R.P. Increased intestinal ABCA1 expression contributes to the decrease in cholesterol absorption after plant stanol consumption. FASEB J. 2002, 16, 1248-1253. [CrossRef] [PubMed]

25. Untergasser, A.; Nijveen, H.; Rao, X.; Bisseling, T.; Geurts, R.; Leunissen, J.A.M. Primer3Plus, an enhanced web interface to Primer3. Nucleic Acids Res. 2007, 35, W71-W74. [CrossRef] [PubMed]

(C) 2018 by the authors. Licensee MDPI, Basel, Switzerland. This article is an open access article distributed under the terms and conditions of the Creative Commons Attribution (CC BY) license (http:/ / creativecommons.org/licenses/by/4.0/). 